\title{
The Second Interaction (Cross) Virial Coefficient for Moist Air
}

\author{
Richard W. Hyland and Arnold Wexler
}

\author{
Institute for Basic Standards, National Bureau of Standards, Washington, D.C. 20234
}

(October 16, 1972)

\begin{abstract}
The results of calculations of the second interaction (cross) virial coefficient $B_{a w}$ for water vapor and air, based on enhancement data obtained at NBS at 30,40 , and $50{ }^{\circ} \mathrm{C}$, are presented. Comparisons are made with the results of calculations based on the enhancement data of Politzer and Strebel, Webster, and Goff et al. and with the results of the theoretical calculations of Mason and Monchick and of Chaddock. An empirical equation is given for interpolation and extrapolation.

The random (one standard deviation) uncertainty in the mean values of $B_{a w}$, arising from the scatter of previously obtained NBS values of the enhancement factor, is estimated to range from 0.7 percent at $30{ }^{\circ} \mathrm{C}$ to 1.4 percent of $50{ }^{\circ} \mathrm{C}$. The estimated systematic uncertainties range from 4 percent at $30{ }^{\circ} \mathrm{C}$ to 6 percent at $50^{\circ} \mathrm{C}$, respectively.
\end{abstract}

Key words: Interaction virial coefficients; moist air; second virial coefficient; virial coefficients; water vapor.

\section{Introduction}

The water vapor content of real gases, and of air in particular, saturated under known conditions of pressure and temperature, is not predicted adequately by ideal gas laws [1]. ${ }^{1}$ In air, the deviations from ideality must be accounted for in order to obtain accuracies better than 0.5 percent at pressures as low as 900 millibars [2]. On any isotherm, the saturated water vapor content increases with pressure to some, as yet, undetermined limit, in a manner consistent with that described by Haar and Sengers [3]. For example, at $0{ }^{\circ} \mathrm{C}$ and 200 bars, the water vapor concentration or density in air is about twice that of the pure phase.

This increase in water vapor content with pressure is the algebraic sum of the increases in apparent vapor pressure because of the superimposed pressure of air (the Poynting effect), and the Van der Waals type interactions between different molecular species, and the decrease in apparent vapor pressure due to the solution of the air in the liquid water (the Henry's law effect). Of the three the largest is due to the nonideality of the gas phase (the Van der Waals type interactions).

Given a real gas equation of state of a water vaporair mixture, say an equation expressed in virial form, it is possible to derive theoretically an expression for the saturation water vapor content of the gas mixture as a function of the mole fraction of the constituents, the parameters of state, and the virial coefficients. In such a formulation, the air-water

\footnotetext{
' Figures in brackets indicate the literature references at the end of this paper
}

interactions are in large part characterized by the second cross virial interaction term for the air and water molecules. Unfortunately there are no definitive values for the second cross interaction virial coefficients, although previously obtained values [2] may be sufficient for some applications.

Attempts have been made to derive second cross interaction virial coefficients from statistical mechanics [4, 5]. However, the assumptions (form of potential) on which these derivations are based are far from exact so that the predicted coefficients are of limited value. What are needed are good experimental values of the second (cross) interaction coeffcients. Recently, Hyland and Wexler [6] at NBS have reported precise experimental values of enhancement factors for water vapor in $\mathrm{CO}_{2}$-free $\left(\mathrm{CO}_{2}\right.$ content on the order of $2 \mathrm{ppm}$ ) air at temperatures of 30,40, and $50{ }^{\circ} \mathrm{C}$. It is the purpose of this paper to use these new data, as well as the limited older data in the literature, in order to compute values of the second interaction virial coefficient. The formal derivations and basic experiments strictly apply to $\mathrm{CO}_{2}$-free air. This limitation is unimportant when using the $\boldsymbol{B}_{a w}$ values in real air situations, as any errors introduced by the roughly $300 \mathrm{ppm}$ of $\mathrm{CO}_{2}$ molecules should be well within the limits caused by the uncertainties in $\boldsymbol{B}_{\text {aw }}$.

\section{Theory}

\subsection{General Considerations}

We will derive an equation which relates the interaction virial coefficient to the enhancement factor, 
thermodynamic parameters of state, and several physical constants. ${ }^{2}$

Initially, it should be stated that the treatment of air as a single-component gas leads to no theoretical inconsistencies, for the following reasons: (1) Over the experimental range of temperatures, we can ignore chemical reactions. (2) The experiments involved a continuous air flow over the liquid surface, so that the molar ratios of the air components are constant, for all experimental conditions of pressure and temperature, once equilibrium has been established. (3) We deal with only the chemical potential of the water in each phase, and since the required chemical potential difference in the liquid phase depends only on the mole fraction of water (see eq (19)) and not on the amount of dissolved species, it doesn't matter that the gas mixture dissolved in the water is of different composition than that of the gas-phase air. (This difference arises because the degree of absorption in water varies from one air component to the next.) Thus, in this paper, it will be assumed that air acts as a single component substance with a known molecular weight.

Let air be in thermodynamic equilibrium with a surface of the condensed water substance. The chemical potential $\mu_{i}$ of each component in the gas phase is equal to that in the condensed phase. For our purposes we need only examine the chemical potential of the water, thus

$$
\mu_{w}^{g}\left(T, P, n_{w}^{g}, n_{a}^{g}\right)=\mu_{w}^{c}\left(T, P, n_{w}^{c}, n_{a}^{c}\right)
$$

where superscripts $g$ and $c$ designate the gaseous and condensed phases, $T$ is the thermodynamic temperature, $P$ the total system pressure, $n_{w}^{\prime<}$ (where $\dot{k}=g$ or $c$ ) is the number of moles of water, and $n_{a}^{k}$ is the number of moles of air. Water is a vapor in the gas phase, and either liquid or solid (ice) in the condensed phase.

In the equations which follow, the independent variables are always $P, T$, and $n_{i}^{k}$, whether stated explicitly or not. It will be understood that the variables which do not explicitly appear are being held constant, so that subscripts are unnecessary for that purpose.

Consider the difference in chemical potential in each phase between pressure states $P_{1}$ and $P_{2}$. We may write

$$
\mu_{w}^{y}\left(P_{2}\right)-\mu_{w}^{g}\left(P_{1}\right)=\mu_{w}^{c}\left(P_{2}\right)-\mu_{w}^{c}\left(P_{1}\right)
$$

We now write

$$
\mu_{w}^{k}=\frac{\partial G^{k}}{\partial n_{w}^{k}}
$$

(see e.g., [7]) where $G^{k}$ is the total Gibbs free energy of either the gas or condensed phase.

To obtain $G^{k}$ we use the thermodynamic relationship

\footnotetext{
2 The theoretical basis for our work, which is reviewed below, is discussed in most good thermodynamics texts. It has been used in various derivations similar to ours, for example, by Haar and Sengers [3], and Goff and Bates [37].
}

$$
V^{k}=\frac{\partial G^{k}}{\partial P}
$$

where $V^{k}$ is the total volume of the phase. The Gibbs free energy difference between states $P_{1}$ and $P_{2}$, obtained by integrating eq (4), is

$$
G^{k}\left(P_{2}\right)-G^{k}\left(P_{1}\right)=\int_{P_{1}}^{P_{2}} V^{k} d P .
$$

Differentiating with respect to $n_{w}^{k}$ it follows that

$$
\begin{aligned}
\mu_{w}^{k}\left(P_{2}\right)-\mu_{w}^{k}\left(P_{1}\right)=\frac{\partial}{\partial n_{w}^{k}} & {\left[G^{k}\left(P_{2}\right)-G^{k}\left(P_{1}\right)\right] } \\
= & {\left[\frac{\partial}{\partial n_{w}^{k}}\left(\int_{P^{1}}^{P_{2}} V^{k} d P\right)\right] . }
\end{aligned}
$$

Substituting eq (6) into (2) yields

$$
\left[\frac{\partial}{\partial n_{w}^{g}}\left(\int_{P_{1}}^{P_{2}} V^{y} d P\right)\right]=\left[\frac{i \partial}{\partial n_{w}^{c}} \int_{P_{1}}^{P_{2}} V^{c} d P\right] .
$$

\subsection{Gas Phase}

The equation of state of a gas may be expressed in virial form as a power series in reciprocal molar volume

$$
\frac{P v}{R T}=1+\frac{B}{v}+\frac{C}{v^{2}}+\ldots
$$

or as a power series in pressure

$$
\frac{P v}{R T}=1+B^{\prime} P+C^{\prime} P^{2}+\ldots
$$

where $P$ is the total pressure, $T$ is the absolute thermodynamic temperature, $v$ is the molar volume, $R$ is the gas constant, $B$ and $B^{\prime}$ are second virial coefficients, and $C$ and $C^{\prime}$ are third virial coefficients. In the enhancement measurements considered in this paper, volume is not one of the experimental parameters. For this reason eq $(8 b)$ is used in our derivation.

The virial coefficients of the pressure series are related to those of the volume series by

and

$$
B^{\prime}=\frac{B}{R T}
$$

$$
C^{\prime}=\frac{C-B^{2}}{(R T)^{2}}
$$

The virial coefficients are functions only of temperature; those of eq (8a) are derivable from statistical mechanical relationships [8] if the form of the intermolecular potential is known. (A very large "if", indeed! See, for example, Hanley and Klein [9]). The second virial coefficients may be considered to express the effects of interactions between two molecules, the third virial coefficients may be considered to express 
the effects of interactions among three molecules, and so forth. The number of terms or coefficients necessary to adequately represent $P v / R T$ will depend on the gas (or gases) involved and the $P v T$ state.

If the gas under consideration is a mixture, then the coefficients $B, C, B^{\prime}, C^{\prime}$, etc., become mixture virial coefficients $B_{\text {mix }}, C_{\text {mix }}$, etc., and can be written in terms of the mole fractions of the pure components, the virial coefficients of the pure components, and quantities called interaction (cross) virial coefficients. For a two-component gas mixture, and in particular for water vapor-air mixtures, statistical mechanics shows that [8]

$B_{\text {mix }}=x_{a}^{2} B_{a a}+2 x_{a} x_{w} B_{a w}+x_{w}^{2} B_{w w}$

$C_{\text {mix }}=x_{a}^{3} C_{a a a}+3 x_{a} x_{w}^{2} C_{a w w}+3 x_{a}^{2} x_{w} C_{a a w}+x_{w}^{3} C_{w w w}$

where $x_{a}$ and $x_{w}$ are the mole fractions of air and water vapor, $B_{a a}$ and $B_{w w}$ are the second virial coefficients for pure air and pure water vapor, and $C_{a a a}$ and $C_{w w w}$ are the third virial coefficients for pure air and pure water vapor. $B_{a w}$ is the second interaction virial coefficient expressing the effects of interaction between an air molecule and a water molecule. $C_{a a w}$ is the third interaction virial coefficient expressing the effects of interaction between two air molecules and one water molecule whereas $C_{a w w}$ is the third interaction virial coefficient expressing the effects of interaction between two water molecules and one air molecule.

The mole fractions of air and water vapor are given by

$$
x_{a}=\frac{n_{a}}{n_{a}+n_{w}}
$$

and

$$
x_{w}=\frac{n_{w}}{n_{a}+n_{w}} .
$$

The molar volume $v_{\text {mix }}$ is related to the total volume $V_{\text {mix }}$ by

$$
V_{\text {mix }}=\left(n_{a}+n_{w}\right) v_{\text {mix }}
$$

where $n_{a}$ and $n_{w}$ are the number of moles of air and water vapor, respectively, in the total volume $V_{\text {mix }}$.

Substituting eqs (10), (9), (8c), and (8d) into (8b) we obtain

$$
\begin{aligned}
V_{\text {mix }}= & \left(n_{a}+n_{w}\right) \frac{R T}{P}+\left[\frac{n_{a}^{2}}{n_{a}+n_{w}} B_{a a}\right. \\
& \left.+\frac{2 n_{a} n_{w}}{n_{a}+n_{w}} B_{a w}+\frac{n_{w}^{2}}{n_{a}+n_{w}} B_{w w}\right] \\
& +\left[\frac{n_{a}^{3}}{\left(n_{a}+n_{w}\right)^{2}} C_{a a a}+\frac{3 n_{a} n_{w}^{2}}{\left(n_{a}+n_{w}\right)^{2}} C_{a w w}\right. \\
& +\frac{3 n_{a}^{2} n_{w}}{\left(n_{a}+n_{w}\right)^{2}} C_{a a w}+\frac{n_{w}^{3}}{\left(n_{a}+n_{w}\right)^{2}} C_{w w w}
\end{aligned}
$$

$$
\begin{aligned}
& -\frac{n_{a}^{4}}{\left(n_{a}+n_{w}\right)^{3}} B_{a a}^{2}-\frac{n_{w}^{4}}{\left(n_{a}+n_{w}\right)^{3}} B_{w w}^{2} \\
& -\frac{4 n_{a}^{3} n_{w}}{\left(n_{a}+n_{w}\right)^{3}} B_{a a} B_{a w}-\frac{4 n_{a} n_{w}^{3}}{\left(n_{a}+n_{w}\right)^{3}} B_{w w} B_{a w} \\
& \left.-\frac{4 n_{a}^{2} n_{w}^{2}}{\left(n_{a}+n_{w}\right)^{3}} B_{a w}^{2}-\frac{2 n_{a}^{2} n_{w}^{2}}{\left(n_{a}+n_{w}\right)^{3}} B_{a u} B_{w w}\right] \frac{P}{R T} \\
& +\ldots
\end{aligned}
$$

Now $V_{\text {mix }}=V^{g}$; therefore eq (11) may be substituted into the left-hand side of eq (7). We let $P_{1}$ be the pure phase saturation vapor pressure $e_{s}(T)$ of the water substance and $P_{22}$ be any other greater total pressure $P$. When the total pressure $P$ reduces to $e_{s}$, then $x_{a}=0$ and $x_{w}=1$. For the sake of simplicity, the superscript $g$ will be deleted. After performing the integration and then the differentiation the left-hand side of eq (7) becomes

$$
\begin{gathered}
{\left[\frac{\partial}{\partial n_{w}} \int_{e_{s}}^{P} V_{\text {mix }} d P\right]=R T \ln \frac{x_{w} P}{e_{s}}-x_{a}^{2} B_{a a} P+2 B_{a w} x_{a}^{2} P} \\
+\left(P-e_{s}-x_{a}^{2} P\right) B_{w w}-\left(C_{w w w}-B_{w w}^{2}\right) \frac{e_{s}^{2}}{2 R T} \\
+\left[C_{w w w} \frac{\left(1+2 x_{a}\right)\left(1-x_{a}\right)^{2}}{2}-C_{a a a} x_{a}^{3}+3 C_{a w w} x_{a}^{2}\left(1-x_{a}\right)\right. \\
-C_{a a w} \frac{3 x_{a}^{2}\left(1-2 x_{a}\right)}{2}-B_{w w}^{2} \frac{\left(1+3 x_{a}\right)\left(1-x_{a}\right)^{3}}{2} \\
\left.-B_{a a} B_{w w} x_{a}^{2}\left(1-3 x_{a}\right)\left(1-x_{a}\right)+B_{a u}^{2} \frac{3 x_{a}^{4}}{2}\right] \frac{P^{2}}{R T} \\
+\left[B_{a a} \frac{2 x_{a}^{3}\left(2-3 x_{a}\right) P^{2}}{R T}+B_{w w} \frac{6 x_{a}^{2}\left(1-x_{a}\right)^{2} P^{2}}{R T}\right] B_{a w} \\
+B_{a w}^{2} \frac{2 x_{a}^{2}\left(1-x_{a}\right)\left(1-3 x_{u}\right) P^{2}}{R T} .
\end{gathered}
$$

The ratio $\frac{x_{w} P}{e_{s}}$ which appears in eq (12) will be called the "enhancement factor" and be designated by the symbol $f$. It has been variously called "the coefficient $f$," "the function $f$," and "the correction factor $f$ " $[2,10,11]$. It is closely related to the "vapor concentration enhancement" of Haar and Sengers [3]. Thus

$$
f=\frac{x_{w} P}{e_{s}}
$$

The quantity $x_{w} P$ may be thought of as an "effective" vapor pressure of the water substance in a real gas 
mixture analogous to a partial pressure in an ideal gas mixture. As $P$ approaches $e_{s}, x_{w}$ approaches unity, and at $P=e_{s}$ and $x_{w}=1$, the enhancement factor $f$ becomes unity.

\subsection{Condensed Phase}

We will confine our consideration of the condensed phase to the liquid state. Consider the right-hand side of eq (7) which expresses the difference in chemical potential for the water substance in the condensed phase between two pressure states $P_{1}$ and $P_{2}$. As before, we let $P_{1}$ be the pure phase saturation vapor pressure $e_{s}(T)$ of the water substance and $P_{2}$ be any other greater pressure $P$. Performing the differentiation yields

$\mu_{w}^{c}\left(T, P, n_{w}^{c}, n_{a}^{c}\right)-\mu_{w}^{c}\left(T, e_{s}, n_{w}^{c}, 0\right)=\frac{\partial}{\partial n_{w}^{c}} \int_{e_{s}}^{P} V^{c} d P$

where $V^{c}$ is the total volume of the condensed phase (i.e., liquid water containing dissolved air), and where we have emphasized that at $P_{1}=e_{s}, n_{a}^{c}=0$. Thus

$$
\mu_{w}^{c}\left(e_{s}\right)=\mu_{w}^{1}\left(e_{s}\right)
$$

where $\mu_{w}^{1}\left(e_{s}\right)$ is the chemical potential of the pure phase liquid water substance at pressure $e_{s}$.

Consider now the pure phase (single component) liquid water substance at the same pressure states $P$ and $e_{s}$. The difference in chemical potential is

$$
\mu_{w}^{1}(P)-\mu_{w}^{1}\left(e_{s}\right)=\int_{e_{s}}^{P} v_{w}^{1} d P
$$

where $v_{w}^{1}$ is the molar volume of pure phase liquid water.

Combining eqs (14), (15), and (16) yields

$$
\mu_{w}^{c}(P)-\mu_{w}^{1}(P)=\frac{\partial}{\partial n_{w}^{c}} \int_{e_{s}}^{P} V^{c} d P-\int_{e_{s}}^{P} v_{w}^{1} d P
$$

or

$$
\frac{\partial}{\partial n_{w}^{c}} \int_{e_{s}}^{P} V^{c} d P=\int_{e_{s}}^{P} v_{w}^{1} d P+\mu_{w}^{c}(P)-\mu_{w}^{1}(P) .
$$

The laws of dilute solutions [7] predict that for a solution of dissolved air in water the chemical potential of the solvent, in this case liquid water, at pressure $P$ differs from that of the pure phase of the same substance under the same pressure by an amount given by

$$
\mu_{w}^{c}(P)-\mu_{w}^{1}(P)=R T \ln x_{w}^{c}+C
$$

where $x_{w}^{c}$ is the mole fraction of water in the solution, and $C$ is a corrective term expressing the excess chemical potential of a real solution over that predicted by the laws of ideal dilute solutions.

Substituting eqs (18) and (17b) into (14) one obtains

$$
\mu_{w}^{c}(P)-\mu_{w}^{c}\left(e_{s}\right)=\int_{e_{S}}^{P} v_{w}^{1} d P+R T \ln x_{w}^{c}+C .
$$

Because $x_{w}^{c}+x_{a}^{c}=1$ we may write

$$
\ln x_{w}^{c}=\ln \left(1-x_{a}^{c}\right) \text {. }
$$

For very dilute solutions ${ }^{3}$ Henry's law may be used to calculate $x_{a}^{c}$, i.e.,

$$
x_{a}^{c}=k(T, P) x_{a}^{g} P
$$

where $k(T, P)$ is the Henry's law "constant" which is a function of $T$ and $P$, and $x_{a}^{g}$ is the mole fraction of air in the gas phase.

The term $C$ in eq (19) is given by [7]

$$
C=W\left(x_{a}^{c}\right)^{2}
$$

where $W$ is a function of the interaction energies of the molecular species in the solution. The term $C$ can be shown [see appendix 1] to be negligible in its contribution to $B_{a w}$ and so is dropped from further consideration.

Equation (19) therefore becomes

$\mu_{w}^{c}(P)-\mu_{w}^{c}\left(e_{s}\right)=\int_{e_{s}}^{P} v_{w}^{1} d P+R T \ln \left(1-k x_{a}^{g} P\right)$.

Kell and Whalley [12] have shown that the specific volume of the pure liquid phase of the water substance can be represented with high accuracy by the following equation of state:

$$
\frac{\bar{V}(t, P)}{\bar{V}(t, 1 \mathrm{~atm})}=1+\sum_{i=0}^{5} \sum_{j=1}^{3} \alpha_{i j} t^{i}\left(P-P_{A}\right)^{j}
$$

where $\bar{V}(t, P)$ is the specific volume at temperature $t$ (Celiuis) and pressure $P, \bar{V}(t, 1 \mathrm{~atm})$ is the specific volume at temperature $t$ and standard atmospheric pressure ( $1 \mathrm{~atm})$, and $P_{A}$ is standard atmospheric pressure. Kell [13] has shown also that

$$
\bar{V}(t, 1 \mathrm{~atm})=\frac{1+b t}{\sum_{n=0}^{5} a_{n} t^{n}} .
$$

\footnotetext{
${ }^{3}$ At pressures up to at least 200 bars and at temperatures from 0 to $100{ }^{\circ} \mathrm{C}$, the mole fraction of water in an equilibrium solution of dissolved air in water is very near unity. At $0^{\circ}$ and 200 bars, $x_{a}^{c}=0.997$.
} 
It therefore follows that

$\mathbf{v}_{w}^{1}=M_{w} \bar{V}(t, P)=$

$$
M_{w}\left[1+\sum_{i=0}^{5} \sum_{j=1}^{3} \alpha_{i j} t^{i}\left(P-P_{A}\right)^{j}\right] \times\left[\frac{1+b t}{\sum_{n=0}^{5} a_{n} t^{n}}\right] .
$$

Let

$$
\int_{e_{s}}^{P} v_{w}^{1} d P=g(T, P) .
$$

Inserting eq (27) into (23) we obtain

$$
\begin{aligned}
{\left[\frac{\partial}{\partial n_{w}^{c}} \int_{\dot{e}_{s}}^{P} V^{c} d P\right]_{T, n_{a}^{c}}=} & \mu_{w}^{c}(P)-\mu_{w}^{c}\left(e_{s}\right)= \\
& g(T, P)+R T \ln \left(1-k x_{a}^{g} P\right)
\end{aligned}
$$

\subsection{Second Interaction Virial Coefficient}

By equating eq (12) and (28) and rearranging terms we obtain

$$
\begin{aligned}
& R T \ln f=g(T, P)+R T \ln \left(1-k x_{a} P\right) \\
& \quad+B_{a u} x_{a}^{2} P-B_{w w}\left(P-e_{s}-x_{a}^{2} P\right) \\
& +C_{a u a} \frac{x^{3} P^{2}}{R T}+C_{a u w} \frac{3 x_{a}^{2}\left(1-2 x_{a}\right) P^{2}}{2 R T}-C_{a w w} \frac{3 x_{u}^{2}\left(1-x_{a}\right) P^{2}}{R T} \\
& -B_{a a}^{2} \frac{3 x_{a}^{4} P^{2}}{2 R T}-C_{w w w} \frac{\left(1+2 x_{a}\right)\left(1-x_{a}\right)^{2} P^{2}-e_{s}^{2}}{2 R T}
\end{aligned}
$$$$
\begin{aligned}
& -B_{a a} B_{w w} \frac{x_{a}^{2}\left(1-3 x_{a}\right)\left(1-x_{a}\right) P^{2}}{R T} \\
& -B_{w w}^{2} \frac{e_{s}^{2}-\left(1+3 x_{a}\right)\left(1-x_{a}\right)^{3} P^{2}}{2 R T} \\
& +B_{a w}\left[-2 x_{a}^{2} P-B_{a a} \frac{2 x_{a}^{3}\left(2-3 x_{a}\right) P^{2}}{R T}\right. \\
& \left.+B_{w w} \frac{6 x_{a}^{2}\left(1-x_{u}\right)^{2} P^{2}}{R T}\right] \\
& -B_{a w}^{2} \frac{2 x_{a}^{2}\left(1-x_{a}\right)\left(1-3 x_{a}\right) P^{2}}{R T} .
\end{aligned}
$$

For the sake of simplicity in nomenclature, all superscripts have been omitted, it being understood, however, that mole fractions $x_{a}$ and $x_{w}$ refer only to the gas phase. Let

$$
\begin{aligned}
\alpha=g(T, P)+R T \ln (1- & \left.k x_{u} P\right)+B_{a a} x_{u}^{2} P \\
& -B_{w w}\left(P-e_{s}-x_{u}^{2} P\right)
\end{aligned}
$$

$$
\begin{gathered}
\beta=C_{a a a} \frac{x_{a}^{3} P^{2}}{R T}+C_{a a w} \frac{3 x_{a}^{2}\left(1-2 x_{a}\right) P^{2}}{2 R T} \\
-C_{a w w} \frac{3 x_{a}^{2}\left(1-x_{a}\right) P^{2}}{R T} \\
-B_{a a}^{2} \frac{3 x_{a}^{4} P^{2}}{2 R T}-C_{w w w} \frac{\left(1+2 x_{a}\right)\left(1-x_{a}\right)^{2} P^{2}-e_{s}^{2}}{2 R T} \\
-B_{a a} B_{w w} \frac{x_{a}^{2}\left(1-3 x_{a}\right)\left(1-x_{a}\right) P^{2}}{R T} \\
\quad-B_{w w}^{2} \frac{e_{s}^{2}-\left(1+3 x_{a}\right)\left(1-x_{a}\right)^{3} P^{2}}{2 R T} \\
\begin{array}{c}
\begin{array}{l}
2 R \\
=
\end{array}=-2 x_{a}^{2} P \\
\delta=
\end{array} \\
\phi=B_{a a} \frac{2 x_{a}^{3}\left(2-3 x_{a}\right) P^{2}}{R T}-B_{w w} \frac{6 x_{a}^{2}\left(1-x_{a}\right)^{2} P^{2}}{R T} \\
\epsilon=\frac{-2 x_{a}^{2}\left(1-x_{a}\right)\left(1-3 x_{a}\right) P^{2}}{R T}
\end{gathered}
$$

then

$$
R T \ln f=\gamma+\phi B_{a w}+\epsilon B_{a w}^{2}
$$

so that

$$
B_{a w}=-\frac{\phi}{2 \epsilon}-\frac{1}{2}\left[\left(\frac{\phi}{\epsilon}\right)^{2}-\frac{4}{\epsilon}(\gamma-R T \ln f)\right]^{1 / 2}
$$

The quadratic term appearing in eq (29i) introduces a small correction into the calculated value of $B_{a w}$. Therefore the value of $B_{a w}$ obtained from eq (29i) without that term must be nearly the same as that calculated from eq (30). It may be shown that this condition is satisfied only if the minus sign is used in front of the radical in eq (30).

\section{Sources of Data}

\subsection{Virial Coefficients}

There are several sources of data for the second and third virial coefficients of air [14, 15, 16]. Probably the best and most up to date values of $B_{a a}$ are those of Sengers et al. [16] which cover the temperature range from 100 to $1400 \mathrm{~K}$. Sengers et al. assign a standard deviation of $0.4 \mathrm{~cm}^{3} / \mathrm{mol}$ to $B_{a a}$. We have chosen three sigmas as our best estimate of the maximum systematic error, i.e., $1.2 \mathrm{~cm}^{3} / \mathrm{mol}$. The Hilsenrath et al. [14] values of $C_{a a a}$ are used here. These range from 90 to $1500 \mathrm{~K}$. We have compared these values with those of Hall and Ibele [15] over temperatures from 0 to $100{ }^{\circ} \mathrm{C}$, our range of interest. The two sets disagree 
by about 10 percent. This disparity was arbitrarily increased to 15 percent and assigned as the estimated systematic uncertainty in $C_{\text {aaa }}$.

The values given by Goff [2] are used for the second and third virial coefficients of water vapor. Wexler and Greenspan [17] recently have shown that from 0 to $100{ }^{\circ} \mathrm{C}$ the Goff values lead to highly precise correlations of theoretical and experimental values of saturation vapor pressure. Other second and third virial coefficients for water vapor are available but only those of Keyes [18] are both experimentally based and cover our experimental range of interest. Goff assigned tolerances to his values, which he stated were equal to twice his estimated probable error. These were converted to one-sigma errors, and compared to the differences between corresponding values of Keyes and Goff. For $B_{w w}$, the agreement between Keyes and Goff, below $70{ }^{\circ} \mathrm{C}$, is better than 2 percent, while the Goff one-sigma uncertainties range from 8 to 2 percent between 30 and $60{ }^{\circ} \mathrm{C}$. It was felt that the more conservative Goff uncertainties were appropriate here, and as estimates of the maximum systematic uncertainties in $B_{w w}$ we used three-sigma errors. In the case of $C_{w w w}$ below $70{ }^{\circ} \mathrm{C}$, the Keyes and Goff values agree to about 45 percent, whereas the one-sigma errors computed from Goff range from 200 percent at $30{ }^{\circ} \mathrm{C}$ to 52 percent at 70 ${ }^{\circ} \mathrm{C}$. These are felt to be overly conservative. Thus the difference between the Keyes and Goff values was taken as an estimate of the systematic uncertainty in $C_{\text {www. }}$.

Mason and Monchick [5] and Hyland and Mason [19] give the only known values of $C_{a a w}$ and $C_{a w w}$, respectively. ${ }^{4}$ These are theoretical calculations based on the Lennard-Jones (12-6) potential, the first covering the temperature range -80 to $+300{ }^{\circ} \mathrm{C}$, the second from 0 to $100{ }^{\circ} \mathrm{C}$. For purposes of this analysis we ascribe an uncertainty of 50 percent in these values although there is no genuinely sound basis for this choice, and the errors may be larger.

Interpolation equations for the various virial coefficients are tabulated in appendix 2.

\subsection{Saturation Vapor Pressure}

The following equation, formulated by Wexler and Greenspan [17], is used to calculate $e_{s}$, the saturation vapor pressure of water:

$$
\ln e_{s}=\sum_{i=0}^{5} E_{i} T_{48}^{i-1}+B \ln T_{48}
$$

where $T_{48}$ is the absolute temperature on the International Practical Temperature Scale of 1948 [20, 21] and $e_{s}$ is expressed in pascals. ${ }^{5}$ The coefficients $E_{i}$ and $B$ are given in table 1 .

${ }^{4}$ Incorrect values of $C_{\text {wru }}$ are listed in table 1 of the paper by Hyland and Mason. A $B_{u r i}^{2}$ term was omitted in the calculation. Although the error propagates through the paper, the preferred $C_{\text {uxw }}$ values (calculated from viscosities) remain unaltered; the effect on the conclusions of the paper is negligible.

Pascal $=1 \mathrm{~N} / \mathrm{m}^{2}=10^{-5}$ bar $=10^{-2} \mathrm{mb}=7.50062 \times 10^{-2} \mathrm{~mm} \mathrm{Hg}$
TABLE 1. Coefficients to vapor pressure formulation eq $(31)^{\mathrm{a}}$

\begin{tabular}{l|r}
\hline \hline$E_{0}$ & $-7.51152 \times 10^{3}$ \\
$E_{1}$ & $9.65389644 \times 10^{1}$ \\
$E_{2}$ & $2.3998970 \times 10^{-2}$ \\
$E_{3}$ & $-1.1654551 \times 10^{-5}$ \\
$E_{4}$ & $-1.2810336 \times 10^{-8}$ \\
$E_{5}$ & $2.0998405 \times 10^{-11}$ \\
$B$ & $-1.2150799 \times 10^{1}$ \\
\hline
\end{tabular}

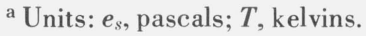

\subsection{Function $g(T, P)$}

The coefficients $\alpha_{i j}, a$ and $b$, given by Kell and Whalley [12] and Kell [13] are tabulated in table 2. These are needed in order to compute $v_{w}^{1}$ using eq (26) which, in turn, permits the computation of $g(T, P)$ using eq (27). Kell and Whalley estimated that the standard deviation of the differences between observed values of $\bar{V}(T, P) / \bar{V}(t, 1 \mathrm{~atm})$ and eq (24) does not exceed $10 \mathrm{ppm}$. Kell estimated that $\bar{V}(t, 1 \mathrm{~atm})$, given by eq (25) has a standard error of $10 \mathrm{ppm}$ or less for temperatures up to $100{ }^{\circ} \mathrm{C}$.

TABle 2. Coefficients to eq $(26)^{a}$

\begin{tabular}{|c|c|c|c|}
\hline & \multicolumn{3}{|c|}{ Coefficients $\alpha_{i j}$} \\
\hline & 1 & 2 & 3 \\
\hline $\begin{array}{l}0 \\
1 \\
2 \\
3 \\
4 \\
5\end{array}$ & $\begin{array}{r}-50.9769 \times 10^{-6} \\
3.71999 \times 10^{-7} \\
-7.01760 \times 10^{-9} \\
6.00227 \times 10^{-11} \\
-3.09041 \times 10^{-13} \\
5.93416 \times 10^{-16}\end{array}$ & \begin{tabular}{r|}
$8.2627 \times 10^{-9}$ \\
$-1.3794 \times 10^{-10}$ \\
$3.4032 \times 10^{-12}$ \\
$-3.6432 \times 10^{-14}$ \\
$2.0836 \times 10^{-16}$ \\
$-4.1744 \times 10^{-19}$
\end{tabular} & $\begin{array}{r}-9.109 \times 10^{-13} \\
2.626 \times 10^{-14} \\
-8.913 \times 10^{-16} \\
11.467 \times 10^{-18} \\
-7.102 \times 10^{-20} \\
14.841 \times 10^{-23}\end{array}$ \\
\hline$n$ & \multicolumn{3}{|c|}{ Coefficients $a_{n}$} \\
\hline $\begin{array}{l}0 \\
1 \\
2 \\
3 \\
4 \\
5\end{array}$ & \multicolumn{3}{|c|}{$\begin{aligned} & 0.9998396 \\
& 1.8224944 \times 10^{-2} \\
- & 7.922210 \times 10^{-6} \\
- & 5.544846 \times 10^{-8} \\
& 1.497562 \times 10^{-10} \\
- & 3.932952 \times 10^{-13}\end{aligned}$} \\
\hline & \multicolumn{3}{|c|}{ Coefficient $b$} \\
\hline & \multicolumn{3}{|c|}{$1.8159725 \times 10^{-2}$} \\
\hline
\end{tabular}

\subsection{Constants}

The solubility data of Winkler [22, 23] for air in water, as reported by Dorsey [24], was used to calculate the Henry's law "constant" $k$ at standard atmospheric pressure. In the absence of any known air data on the pressure dependence of this "constant," it was assumed that the percentage changes in $k$ between the same 
TABLE 3. Henry's law "constants" $\mathrm{k}$ for nitrogen and air dissolved in water $\mathrm{f}$

\begin{tabular}{c|c|c|c|c|c|c|c|c|c}
\hline \multirow{2}{*}{$\begin{array}{c}\text { Temp. } \\
{ }^{\circ} \mathrm{C}\end{array}$} & \multicolumn{3}{|c|}{ Nitrogen $^{\mathrm{a}}$} & \multicolumn{3}{c|}{ Air } & \multicolumn{3}{c}{ Air $^{\mathrm{e}}$} \\
\cline { 2 - 10 } & \multicolumn{3}{|c|}{ Pressure, bars } & \multicolumn{3}{c}{ Pressure, bars } & \multicolumn{3}{c}{ Pressure, bars } \\
\cline { 2 - 10 } & 1 & 50 & 100 & $1^{\text {b }}$ & $50^{\text {c }}$ & $100^{\text {d }}$ & 1 & 50 & 100 \\
\hline \multirow{2}{*}{$\mathbf{0}$} & 18.65 & 17.00 & 15.62 & 23.25 & 21.19 & 19.48 & 23.20 & 21.20 & 19.49 \\
5 & 16.42 & 15.11 & 13.96 & 20.45 & 18.82 & 17.39 & 20.53 & 18.81 & 17.37 \\
10 & 14.89 & 13.69 & 12.70 & 18.26 & 16.80 & 15.58 & 18.30 & 16.79 & 15.58 \\
15 & 13.51 & 12.41 & 11.60 & 16.49 & 15.15 & 14.15 & 16.46 & 15.12 & 14.10 \\
20 & 12.52 & 11.42 & 10.72 & 14.93 & 13.62 & 12.78 & 14.96 & 13.75 & 12.88 \\
25 & 11.61 & 10.68 & 10.01 & 13.84 & 12.73 & 11.92 & 13.76 & 12.64 & 11.90 \\
30 & 10.88 & 10.00 & 9.46 & 12.83 & 11.79 & 11.16 & 12.79 & 11.77 & 11.13 \\
35 & 10.23 & 9.44 & 8.97 & 12.00 & 10.08 & 10.53 & 12.02 & 11.10 & 10.52 \\
40 & 9.67 & 9.02 & 8.57 & 11.34 & 10.58 & 10.05 & 11.40 & 10.58 & 10.05 \\
45 & 9.27 & 8.70 & 8.25 & 10.84 & 10.17 & 9.64 & 10.87 & 10.19 & 9.68 \\
50 & 8.90 & 8.44 & 8.00 & 10.44 & 9.90 & 9.39 & 10.39 & 9.89 & 9.38 \\
\hline
\end{tabular}

aData based on solubilities in references [24, 25, 26, 27, 28, 29, 30].

${ }^{\mathrm{b}}$ Data based on solubilities in references [22, 23, 24].

${ }^{\mathrm{c}}$ Calculated by assuming that the percent difference for air is the same as for nitrogen between 50 and 1 bars.

${ }^{\mathrm{d}}$ Calculated by assuming that the percent difference for air is the same as for nitrogen between 100 and 1 bars.

e Calculated from eq (32).

${ }^{\mathrm{f}}$ Units: $k, 10^{-6}$ mole fraction per bar; $P$, bars.

pressure levels at given temperatures were the same for air as for nitrogen, for which there are solubility data both at atmospheric pressure [25, 26, 27, 28], and at high pressure for temperatures above $20^{\circ} \mathrm{C}[24,29$, $30]$. Using solubility data for nitrogen in water and converting these to $k$, values for air were extropolated accordingly. Below $20^{\circ} \mathrm{C}$, solubilities of nitrogen in water were calculated using the method of Krichevsky and Kasarnovsky [31] and the fugacities reported by Demming and Shupe [32]. The polynomial

$$
10^{6} k=\sum_{i=0}^{3} C_{i} t^{i}
$$

was fitted by the method of least squares to the Henry's law "constant" for air in water at 1,50 , and 100 bars, where $k$ is in units of mole fraction per bar, $C_{i}$ are coefficients, and $t$ is the temperature in degrees Celsius. Linear interpolations were employed between isobars. Values of $k$ for nitrogen and air are given in table 3 and for $C_{i}$ in table 4 . The values of $k$ for air are considered uncertain, at most, by 10 percent.

On the unified carbon- 12 scale the molecular weight of water $M_{w}$ is $18.0154 \mathrm{~g} / \mathrm{mol}$ with a maximum total

TABLE 4. Coefficients to eq $(32)^{\mathrm{a}}$

\begin{tabular}{c|c|c|c}
\hline \hline \multirow{2}{*}{$i$} & \multicolumn{3}{|c}{ Pressure, bars } \\
\cline { 2 - 4 } & 1 & 50 & 100 \\
\hline \multirow{2}{*}{0} & 23.195 & 21.197 & 19.493 \\
1 & -0.58037 & -0.51768 & -0.46024 \\
2 & $9.7392 \times 10^{-3}$ & $8.2103 \times 10^{-3}$ & $7.3781 \times 10^{-3}$ \\
3 & $-6.5058 \times 10^{-5}$ & $-4.7585 \times 10^{-5}$ & $-4.4401 \times 10^{-5}$ \\
\hline
\end{tabular}

a Units: $t$, degrees Celsius; $k$, mole fraction per bar. uncertainty of $0.0009 \mathrm{~g} / \mathrm{mol}$ [33]. The gas constant $R$ is equal to 83.1434 bar $\mathrm{cm}^{3} / \mathrm{mol} \mathrm{K}$ with a standard deviation of $0.0035 \mathrm{bar} \mathrm{cm}^{3} / \mathrm{mol} \mathrm{K}$ [34].

\subsection{Enhancement Factor}

The NBS enhancement factor data [6] are given in table 5. It is estimated that the systematic uncertainty in $f$ is 0.07 percent and the random uncertainty is 0.2 percent. Two $30^{\circ} \mathrm{C}$ runs, reported as being suspicious in [6], have not been considered for the calculation of $B_{a w}$.

\section{Results}

Values of $B_{a w}$ calculated from these data using eq $(30)$ are given in table 5 . The values were normalized from the experimental temperature to the nominal isotherm temperature. The changes, where they occur, are small.

Our best estimates of the magnitudes of $B_{a w}$ and associated random uncertainties are represented respectively by the means of the normalized isotherm values and the standard deviations of the mean normalized values. These are reported in table 6 , along with the standard deviations of the individual determinations.

\section{Effect of Third Virial Terms}

Statistical mechanics predicts that the virial coefficients are functions solely of temperature [8]. An apparent dependence of $B_{a w}$ on pressure can be introduced via the calculations if a sufficient number of terms are not included in the truncated infinite series of the equation of state. If this equation were terminated at the second virial term rather than the 
TABLE 5. Second interaction virial coefficients based on NBS enhancement data

\begin{tabular}{|c|c|c|c|c|c|c|c|}
\hline \multirow{4}{*}{$\begin{array}{l}\text { Run } \\
\text { No. }\end{array}$} & $\begin{array}{l}\text { Saturation } \\
\text { temp. }\end{array}$ & $\begin{array}{l}\text { Saturation } \\
\text { vap. press. }\end{array}$ & $\begin{array}{c}\text { Total } \\
\text { pressure }\end{array}$ & \multirow{2}{*}{$\begin{array}{l}\text { Mole fractionl } \\
\text { water vapor }\end{array}$} & \multirow{2}{*}{$\begin{array}{c}\text { Enhancement } \\
\text { factor }\end{array}$} & $\begin{array}{l}\text { Interaction } \\
\text { virial coeff. }\end{array}$ & $\begin{array}{l}\text { Normalized } \\
\text { inter. vir. coeff. }\end{array}$ \\
\hline & ${ }^{\circ} \mathrm{C}$ & mbar & bar & & & $\mathrm{cm}^{3} / \mathrm{mol}$ & $\mathrm{cm}^{3} / \mathrm{mol}$ \\
\hline & $t$ & $e_{\mathrm{s}}$ & $P$ & $x_{w}$ & $f$ & $B_{a w}$ & $B_{a w}$ \\
\hline & \multicolumn{7}{|c|}{ Isotherm temperature, $30^{\circ} \mathrm{C}$} \\
\hline $\begin{array}{l}39 \\
47 \\
42 \\
20 \\
40\end{array}$ & $\begin{array}{l}29.9994 \\
30.0065 \\
29.9999 \\
30.0112 \\
29.9999\end{array}$ & $\begin{array}{l}42.4278 \\
42.4451 \\
42.4290 \\
42.4566 \\
42.4290\end{array}$ & $\begin{array}{l}10.7312 \\
15.1088 \\
19.9344 \\
30.1929 \\
35.5133\end{array}$ & $\begin{array}{r}0.0040827 \\
.0029354 \\
.0022534 \\
.0015317 \\
.0013201\end{array}$ & $\begin{array}{l}1.0326 \\
1.0449 \\
1.0587 \\
1.0893 \\
1.1049\end{array}$ & $\begin{array}{l}-29.962 \\
-29.389 \\
-29.115 \\
-28.988 \\
-28.763\end{array}$ & $\begin{array}{l}-29.962 \\
-29.392 \\
-29.115 \\
-28.944 \\
-28.763\end{array}$ \\
\hline \multicolumn{8}{|c|}{ Isotherm temperature, $40{ }^{\circ} \mathrm{C}$} \\
\hline $\begin{array}{l}34 \\
19 \\
27 \\
22 \\
21\end{array}$ & $\begin{array}{l}40.0104 \\
39.9969 \\
39.9648 \\
40.1505 \\
40.1366\end{array}$ & $\begin{array}{l}73.8143 \\
73.7612 \\
73.6350 \\
74.3673 \\
74.3122\end{array}$ & $\begin{array}{l}14.6417 \\
30.1957 \\
40.4557 \\
50.3962 \\
60.9945\end{array}$ & $\begin{array}{r}0.0052456 \\
.0026497 \\
.0020231 \\
.0016810 \\
.0014285\end{array}$ & $\begin{array}{l}1.0405 \\
1.0847 \\
1.1115 \\
1.1392 \\
1.1725\end{array}$ & $\begin{array}{l}-26.286 \\
-26.978 \\
-26.124 \\
-25.831 \\
-26.158\end{array}$ & $\begin{array}{l}-26.289 \\
-26.977 \\
-26.114 \\
-25.876 \\
-26.199\end{array}$ \\
\hline \multicolumn{8}{|c|}{ Isotherm temperature, $50{ }^{\circ} \mathrm{C}$} \\
\hline $\begin{array}{l}32 \\
37 \\
36 \\
43 \\
46 \\
35 \\
31 \\
33 \\
30 \\
17 \\
16 \\
29 \\
26 \\
23 \\
24 \\
28 \\
25\end{array}$ & $\begin{array}{l}49.9898 \\
49.9942 \\
50.0042 \\
50.0047 \\
49.9971 \\
50.0011 \\
49.9891 \\
50.0064 \\
49.9967 \\
50.0101 \\
50.0050 \\
50.0009 \\
49.9766 \\
50.0049 \\
49.9784 \\
49.9815 \\
49.9788\end{array}$ & $\begin{array}{l}123.3233 \\
123.3503 \\
123.4115 \\
123.4146 \\
123.3680 \\
123.3925 \\
123.3191 \\
123.4250 \\
123.3656 \\
123.4477 \\
123.4164 \\
123.3913 \\
123.2426 \\
123.4158 \\
123.2536 \\
123.2726 \\
123.2561\end{array}$ & $\begin{array}{c}10.5512 \\
10.6310 \\
10.7441 \\
10.7546 \\
10.7953 \\
10.7989 \\
14.6231 \\
14.8620 \\
25.3585 \\
30.1977 \\
30.2324 \\
36.5953 \\
40.8462 \\
50.3229 \\
76.3139 \\
96.9356 \\
102.704\end{array}$ & $\begin{array}{r}0.0120190 \\
.0119361 \\
.0118214 \\
.0117992 \\
.0117446 \\
.0117614 \\
0.0087902 \\
.0086263 \\
.0051773 \\
.0044266 \\
.0044135 \\
.0036782 \\
.0033228 \\
.0027681 \\
.0019376 \\
.0016749 \\
.0015264\end{array}$ & $\begin{array}{l}1.0283 \\
1.0287 \\
1.0292 \\
1.0282 \\
1.0277 \\
1.0293 \\
1.0423 \\
1.0387 \\
1.0642 \\
1.0828 \\
1.0811 \\
1.0909 \\
1.1013 \\
1.1287 \\
1.1997 \\
1.2355 \\
1.2719\end{array}$ & $\begin{array}{l}-23.443 \\
-23.713 \\
-23.915 \\
-22.714 \\
-21.977 \\
-23.946 \\
-27.135 \\
-23.399 \\
-23.186 \\
-25.846 \\
-25.117 \\
-22.605 \\
-22.502 \\
-23.227 \\
-23.088 \\
-22.298 \\
-22.483\end{array}$ & $\begin{array}{l}-23.440 \\
-23.711 \\
-23.916 \\
-22.715 \\
-21.976 \\
-23.946 \\
-27.132 \\
-23.401 \\
-23.185 \\
-25.849 \\
-25.118 \\
-22.605 \\
-22.495 \\
-23.228 \\
-23.082 \\
-22.292 \\
-22.477\end{array}$ \\
\hline
\end{tabular}

TABLE 6. Mean normalized second interaction virial coefficients $\overline{\mathrm{B}}_{\mathrm{aw}}$ based on NBS data

\begin{tabular}{c|c|c|c|c|c}
\hline \hline $\begin{array}{c}\text { Isotherm } \\
\text { Temp. }\end{array}$ & $\begin{array}{c}\text { Mean } \\
\text { normalized } \\
\bar{B}_{a w}\end{array}$ & \multicolumn{2}{|c|}{$\begin{array}{c}\text { Standard deviation } \\
\text { of single } \\
\text { determination }\end{array}$} & \multicolumn{2}{|c}{$\begin{array}{c}\text { Standard deviation } \\
\text { of mean }\end{array}$} \\
\hline${ }^{\circ} \mathrm{C}$ & $\mathrm{cm}^{3} / \mathrm{mol}$ & $\mathrm{cm}^{3} / \mathrm{mol}$ & Percent & $\mathrm{cm}^{3} / \mathrm{mol}$ & Percent \\
\hline 30 & -29.245 & 0.46 & 1.6 & .21 & 0.7 \\
40 & -26.291 & .41 & 1.6 & .18 & .7 \\
50 & -23.595 & 1.35 & 5.7 & .33 & 1.4 \\
\hline
\end{tabular}

third, the terms associated with the parameters $\epsilon$, $\delta$, and $\beta$ would reduce to zero and from eq (29i) we would have

$$
B_{a w}=(R T \ln f-\alpha) / D
$$

The change introduced by using eq (33) instead of (30) is significant as shown graphically in figure 1 using the NBS enhancement data. Because of this the third virial coefficients were included in the calculation of $B_{a w}$, even though there are large uncertainties associated with them. It will be shown that the accuracy in $B_{a w}$ is relatively insensitive to the accuracies of the third virial coefficients.

\section{Error Analysis}

An analysis was made of the effect of suspected systematic and random errors on the accuracy of the values of $\boldsymbol{B}_{a w}$ given in the results.

\subsection{Enhancement Factor}

It can be shown that the uncertainties in the experimental parameters $P, e_{s}$, and $x_{w}$ contribute to the error in $B_{a w}$ primarily from their appearance in the enhancement factor term and negligibility because of their presence in the other terms of eq (30). ${ }^{6}$ Therefore, for

${ }^{6}$ This was checked by making arbitrary changes in these parameters and noting the
corresponding changes in the individual terms contributing to $B_{a w}$, as well as in $B_{a w}$ itself. 


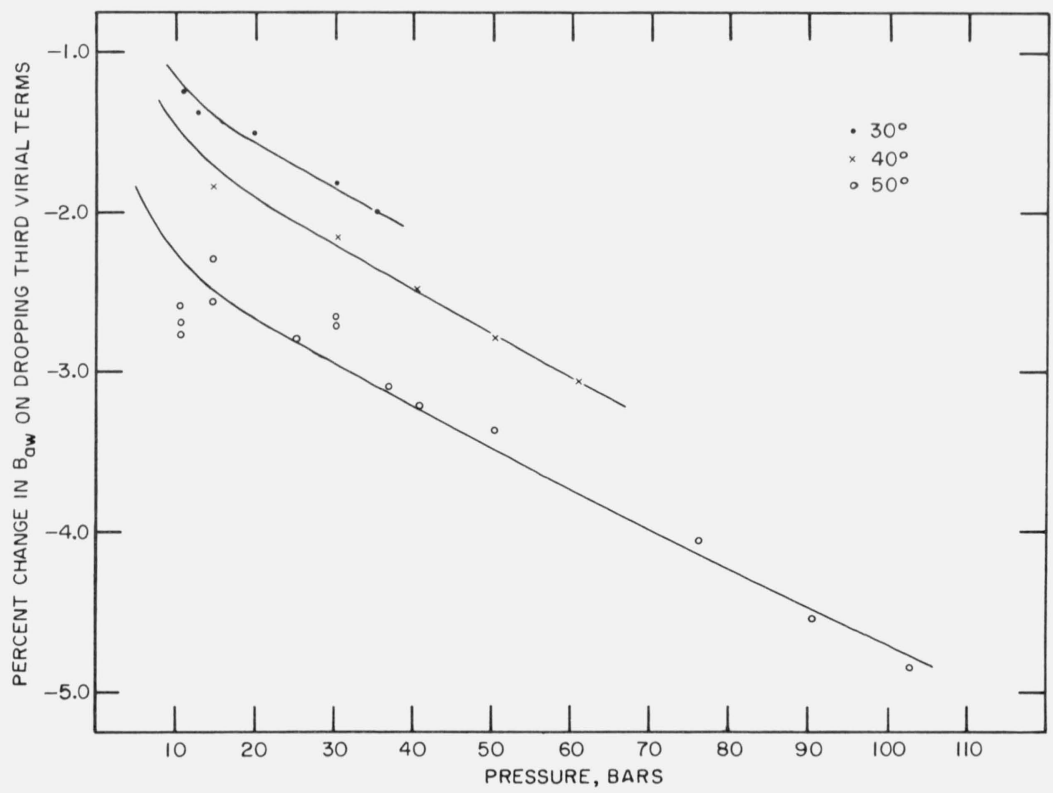

FIGURE 1. The percentage changes in calculated values of $\mathrm{B}_{\mathrm{aw}}$, when third virial terms are dropped from eq (30).

purposes of error analysis, the higher order virial coefficients may be neglecied and eq (33) used with adequate accuracy for examining the effect of an error in $f$ on $B_{a w}$. Differentiating $B_{a w}$ with respect to $f$, replacing the differential with finite increments, and considering only magnitudes, we obtain

$$
\Delta B_{a w}=\frac{R T}{2 P x_{a}^{2} f} \Delta f \approx \frac{R T}{2 P} \frac{\Delta f}{f}
$$

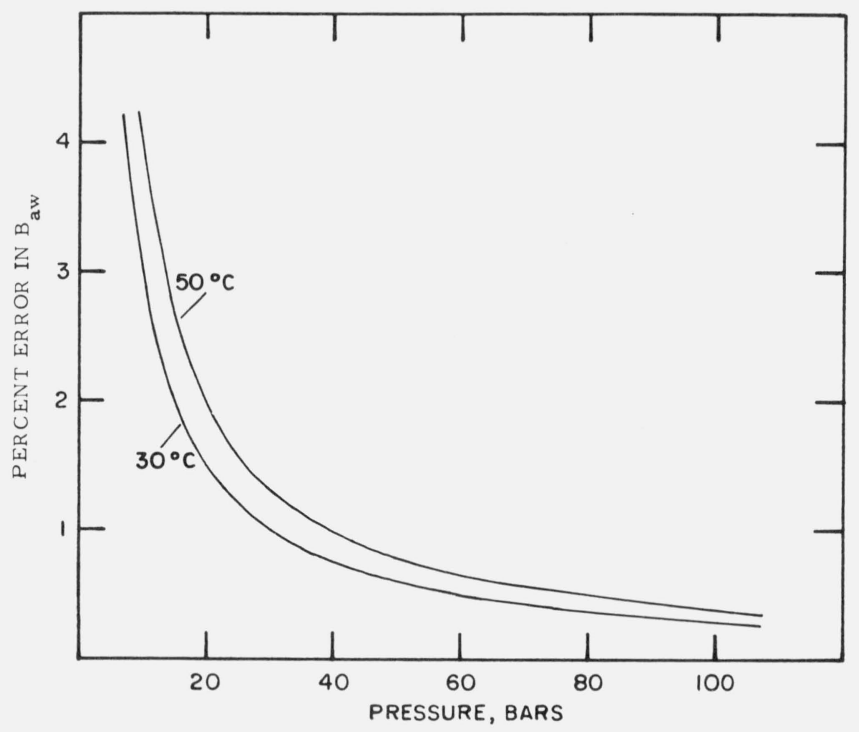

Figure 2. Percentage errors in $\mathrm{B}_{\mathrm{aw}}$ as a function of temperature and pressure, arising from the estimated systematic error of 7 parts in $10^{4}$ in the enhancement factor. where $x_{a}$ is assumed roughly equal to unity. The systematic uncertainty in the NBS values of enhancement factor is 0.07 percent [6]. By substituting this into eq (34), and using the mean values of $B_{a w}$ given in table 6 to convert $\Delta B_{a w}$ to percent, the curves shown in figure 2 were generated. It may be noted that for a fixed relative uncertainty in $f$ the corresponding uncertainty in $B_{a w}$ decreases with increasing pressure. This relationship suggests that for interaction virial coefficient determinations it would be advantageous to perform enhancement measurements at high pressures. However, as we will show below, this gain in accuracy is offset by the increasing uncertainties contributed by the terms in eq (30) containing the third virial coefficients.

\subsection{Virial Coefficients}

The effects of the estimated systematic uncertainties in the virial coefficients (given in sec. 3.1 ) on $B_{a w}$ were calculated using eq (30). The results are given in table 7 at the experimental pressures and temperatures.

\subsection{Henry's Law}

It is shown in appendix 1 that dropping the correction term $C$ to Henry's law, (eq (22)), may lead to an uncertainty in $B_{a w}$ of about 0.13 percent. An uncertainty is contributed also by the "constant" $k$. The second interaction virial coefficient may be written as follows:

$$
B_{a w} \approx \frac{-R T k x_{a} P}{2 x_{a} P}+\text { various terms. }
$$


TABLE 7. Estimated systematic uncertainties in $\mathrm{B}_{\mathrm{aw}}$

\begin{tabular}{|c|c|c|c|c|c|c|c|c|c|c|c|}
\hline \multirow{4}{*}{ Temp. } & \multirow{4}{*}{ Press. } & \multicolumn{8}{|c|}{ Source of error } & \multicolumn{2}{|c|}{ Quadrature $^{\mathrm{e}}$} \\
\hline & & $B_{a a}$ & $B_{w w}$ & $C_{\text {aaa }}$ & $C_{w w w}$ & $C_{\text {aaw }}$ & $C_{a w w}$ & $f$ & Other & \multirow{3}{*}{$\begin{array}{c}\text { Virial } \\
\text { coefficient } \\
\text { errors } \\
\text { only }\end{array}$} & \multirow{3}{*}{$\begin{array}{c}\text { All } \\
\text { errors }\end{array}$} \\
\hline & & \multicolumn{8}{|c|}{ Estimated error in parameter, percent } & & \\
\hline & & $\left({ }^{a}\right)$ & $\left({ }^{b}\right)$ & 15 & $\left({ }^{c}\right)$ & 50 & 50 & .07 & $\left({ }^{\prime}\right)$ & & \\
\hline${ }^{\circ} \mathrm{C}$ & bar & \multicolumn{8}{|c|}{ Estimated error in $B_{u w}$, percent } & \multicolumn{2}{|c|}{$\begin{array}{c}\text { Estimated error in } \boldsymbol{B}_{a w} \\
\text { percent }\end{array}$} \\
\hline 30 & $\begin{array}{l}10.7 \\
19.9 \\
35.5\end{array}$ & $\begin{array}{l}2.0 \\
2.0 \\
2.0\end{array}$ & $\begin{array}{l}1.9 \\
1.1 \\
.68\end{array}$ & $\begin{array}{r}0.14 \\
.26 \\
.47\end{array}$ & $\begin{array}{r}0.05 \\
.03 \\
.02\end{array}$ & $\begin{array}{c}0.42 \\
.81 \\
1.4\end{array}$ & $\begin{array}{r}0.42 \\
.45 \\
.47\end{array}$ & $\begin{array}{l}2.8 \\
1.5 \\
0.85\end{array}$ & $\begin{array}{r}0.14 \\
.14 \\
.14\end{array}$ & $\begin{array}{l}2.8 \\
2.5 \\
2.6\end{array}$ & $\begin{array}{l}4.0 \\
2.9 \\
2.7\end{array}$ \\
\hline 40 & $\begin{array}{l}14.6 \\
40.5 \\
61.0\end{array}$ & $\begin{array}{l}2.2 \\
2.1 \\
2.1\end{array}$ & $\begin{array}{l}1.6 \\
.66 \\
.48\end{array}$ & $\begin{array}{l}.20 \\
.56 \\
.84\end{array}$ & $\begin{array}{l}.08 \\
.04 \\
.03\end{array}$ & $\begin{array}{l}.62 \\
1.7 \\
2.6\end{array}$ & $\begin{array}{l}.66 \\
.71 \\
.75\end{array}$ & $\begin{array}{l}2.4 \\
.85 \\
.57\end{array}$ & $\begin{array}{l}.14 \\
.14 \\
.14\end{array}$ & $\begin{array}{l}2.9 \\
2.9 \\
3.6\end{array}$ & $\begin{array}{l}3.7 \\
3.0 \\
3.6\end{array}$ \\
\hline 50 & $\begin{array}{c}10.6 \\
25.4 \\
50.3 \\
76.3 \\
103\end{array}$ & $\begin{array}{l}2.6 \\
2.5 \\
2.4 \\
2.3 \\
2.3\end{array}$ & $\begin{array}{l}2.5 \\
1.1 \\
0.64 \\
.48 \\
.40\end{array}$ & $\begin{array}{l}.16 \\
.38 \\
.76 \\
1.2 \\
1.6\end{array}$ & $\begin{array}{l}.21 \\
.10 \\
.06 \\
.04 \\
.04\end{array}$ & $\begin{array}{l}0.46 \\
1.2 \\
2.3 \\
3.5 \\
4.8\end{array}$ & $\begin{array}{l}.98 \\
1.0 \\
1.1 \\
1.2 \\
1.2\end{array}$ & $\begin{array}{l}3.8 \\
1.6 \\
0.79 \\
.52 \\
.39\end{array}$ & $\begin{array}{l}.14 \\
.14 \\
.14 \\
.14 \\
.14\end{array}$ & $\begin{array}{l}3.8 \\
3.2 \\
3.6 \\
4.5 \\
5.7\end{array}$ & $\begin{array}{l}5.4 \\
3.6 \\
3.7 \\
4.6 \\
5.7\end{array}$ \\
\hline
\end{tabular}

\footnotetext{
${ }^{\text {a }}$ Estimated $3 \sigma$ error is $1.2 \mathrm{~cm}^{3} / \mathrm{mol}$; error is 17,23 , and 34 percent at 30,40 , and $50{ }^{\circ} \mathrm{C}$, respectively.

${ }^{\mathrm{b}}$ Estimated error is 24,16 , and 11 percent at 30,40 , and $50^{\circ} \mathrm{C}$, respectively.

c Estimated error is nominally 43 percent at 30,40 , and $50{ }^{\circ} \mathrm{C}$.

d Quadrature of errors contributed by Henry's law, gas constant, and ignoring the correction to the law of ideal solutions.

e Computed by the square root of the sum of the squares of the individual terms.
}

Hence, neglecting the sign,

$$
\Delta B_{a w} \approx \frac{R T}{2} \Delta k \approx 13000 \Delta k .
$$

The estimated uncertainty in $k$ is 10 percent. Over the pressure and temperature range of the NBS data, the variation in $k$ is small. With sufficient accuracy for this calculation, $\Delta k=1.1 \times 10^{-6}$ and therefore $\Delta B_{a w}$ $=0.014 \mathrm{~cm}^{3} / \mathrm{mol}$. Assuming a nominal magnitude of $26 \mathrm{~cm}^{3} / \mathrm{mol}$ for $B_{a w}, k$ induces an uncertainty in $B_{a w}$ of about 0.05 percent.

\subsection{Function $g(P, T)$; Gas Constant}

The largest contributions from the term $g(P, T)$ to the uncertainties in $B_{a w}$ arise from uncertainties in the specific volume of water $\bar{V}(t, P)$ and the molecular weight of water, while the largest contribution from the gas constant $R$ arises through the enhancement factor term. The uncertainties in $P$ and $t$ in the NBS data are insignificant in their effect on $\bar{V}(t, P)$. The systematic errors in $\bar{V}(t, P), M_{w}$, and $R$ (secs. 3.3 and 3.4) likewise produce negligible uncertainties in the calculated values of $B_{a w}$.

\subsection{Estimated Systematic Uncertainty in $B_{a w}$}

The estimated systematic uncertainties in the individual parameters at the experimental values of $P$ and $T$ are summarized in table 7 . These were combined by quadrature to give the estimated overall systematic uncertainty in $B_{a w}$. Two quadrature columns are shown. The left column is the estimated uncertainty in the calculated value of $B_{a w}$ contributed solely by the virial coefficient terms whereas the right column is the estimated uncertainty in $B_{a w}$ due to all suspected sources of systematic error. Along each isotherm, as the effect on $B_{a w}$ from the fixed percentage uncertainty in enhancement factor decreases with pressure, the effect from the uncertainties in the virial coefficients increases in such a way as to keep the overall systematic uncertainty in $B_{a w}$ more or less constant over the pressure range considered. The systematic uncertainty increases from 4 percent at $30^{\circ} \mathrm{C}$ to 6 percent at $50^{\circ} \mathrm{C}$, and applies to the mean value of $B_{a w}$ as well as to the individual values.

\subsection{Estimated Random Uncertainty in $B_{a w}$}

The experimental standard deviations of the single determinations and of the mean value of $\boldsymbol{B}_{a w}$ have been given (table 6 ) as our best estimates of the random uncertainties in $B_{a w}$. The random uncertainty in $B_{a w}$ arises mainly from the random error in the enhancement factor. The latter, based on the residual standard deviations of fits of $f$ to a pressure function, is 0.02 percent at $30^{\circ} \mathrm{C}, 0.13$ percent at 40 , and 0.26 percent at $50^{\circ} \mathrm{C}[6]$. The corresponding calculated uncertainty in a single $B_{a w}$ determination, as a function of pressure along each isotherm, is indicated in table 8. Also given for each isotherm is a mean single-determination uncertainty, based on the three tabulated values. This calculated mean value should be comparable to 
TABLE 8. Comparison of estimated random uncertainties in a single determination of $\mathrm{B}_{\mathrm{aw}}$

\begin{tabular}{|c|c|c|c|}
\hline \multirow{2}{*}{ Temp. } & \multirow{2}{*}{$P$} & \multicolumn{2}{|c|}{ Random uncertainty in $B_{a w}$} \\
\hline & & $\begin{array}{l}\text { Based on ran- } \\
\text { dom error in } f^{\text {a }}\end{array}$ & $\begin{array}{l}\text { Based on preci- } \\
\text { cision of } B_{a w}\end{array}$ \\
\hline${ }^{\circ} \mathrm{C}$ & Bar & Percent & Percent \\
\hline \multirow[t]{2}{*}{30} & $\begin{array}{l}10.7 \\
19.9 \\
35.5\end{array}$ & $\begin{array}{r}0.80 \\
.43 \\
.24\end{array}$ & \\
\hline & \multicolumn{2}{|c|}{ Mean 0.49} & 1.6 \\
\hline \multirow[t]{2}{*}{40} & $\begin{array}{l}14.6 \\
40.5 \\
61.0\end{array}$ & $\begin{array}{l}4.4 \\
1.6 \\
1.1\end{array}$ & \\
\hline & \multicolumn{2}{|r|}{ Mean 2.4} & 1.6 \\
\hline \multirow[t]{2}{*}{50} & $\begin{array}{c}10.6 \\
25.4 \\
50.3 \\
76.3 \\
103\end{array}$ & $\begin{array}{r}14.0 \\
5.8 \\
2.9 \\
1.9 \\
1.4\end{array}$ & \\
\hline & \multicolumn{2}{|r|}{ Mean 5.2} & 5.7 \\
\hline
\end{tabular}

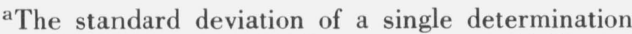
of $f$ is 0.02 percent at $30^{\circ} \mathrm{C}, .13$ percent at $40^{\circ} \mathrm{C}$, and 0.26 percent at $50^{\circ} \mathrm{C}$. [6].

the experimentally determined precision of a single $B_{a w}$ determination. The latter values are repeated in table 8 , and it is seen that the calculated and experimental random uncertainties are in reasonably good agreement.

\section{Comparisons}

There are three known experimental determinations of the enhancement of water vapor in air from which the interaction virial coefficient may be calculated. Politzer and Strebel [35] performed single saturation isotherm experiments at 50 and $70^{\circ} \mathrm{C}$ at total pressure up to 200 bars. Webster [36] obtained values at -35 , $-20,0$ and $15{ }^{\circ} \mathrm{C}$ at total pressures up to 200 bars, also using the single isotherm saturation method. Goff et al. $[37,38,39]$ measured a quantity closely related to the interaction virial coefficient, from 5 to $25^{\circ} \mathrm{C}$ at total pressures near one bar.

Values of $B_{a w}$ were computed from the Politzer and Strebel data using the same procedures, constants and virial coefficients that had been used with the NBS data. The $50^{\circ} \mathrm{C}$ data of Politzer and Strebel yielded values of $B_{a w}$ that appear to scatter independently of pressure around an average value, except for four points at 12 bars and below. These four points are suspect and so were discarded. The mean and the standard deviation of the mean are given in table 9 . The $70{ }^{\circ} \mathrm{C}$ data of Politzer and Strebel show a strong monotonic pressure dependence, contrary to the predictions of theory. It is probable that there is a significant systematic error in the measurements although the source of this error is not obvious. Because of this, the $70{ }^{\circ} \mathrm{C}$ data were excluded from further consideration.

$B_{a w}$ was computed similarly from Webster's data for each of his isotherms. At -35 and $-20^{\circ} \mathrm{C}$ a minor change was introduced into the calculations to allow for the solid state of the condensed phase. This involved the use for the Henry's law "constant" the value for water at $0^{\circ} \mathrm{C}$ and $1 \mathrm{bar}$ and for $e_{s}$ the appropriate values of saturation vapor pressure with respect to ice [40]. The resultant error from the choice of $k$ is negligible; in fact, within the uncertainty of the Webster measurements the Henry's law "constant" could be ignored. The mean value of $B_{a w}$ for each temperature, and the standard deviation of the mean are given in table 9 .

TABLE 9. Interaction virial coefficients from literature data

\begin{tabular}{|c|c|c|c|c|c|c|c|c|}
\hline \multirow{3}{*}{$\begin{array}{l}\text { Temperature } \\
{ }^{\circ} \mathrm{C}\end{array}$} & \multicolumn{8}{|c|}{ Source } \\
\hline & \multicolumn{2}{|c|}{ Webster } & \multicolumn{2}{|c|}{ Politzer and Strebel } & \multicolumn{2}{|c|}{ Goff } & \multirow{2}{*}{$\begin{array}{c}\text { Mason and } \\
\text { Monchick }\end{array}$} & \multirow{2}{*}{$\begin{array}{c}\text { Chaddock }^{b} \\
\\
-B_{a w} \\
\mathrm{~cm}^{3} / \mathrm{mol}\end{array}$} \\
\hline & $\begin{array}{c}-\bar{B}_{a w}{ }^{\mathrm{a}} \\
\mathrm{cm}^{3} / \mathrm{mol}\end{array}$ & $\begin{array}{c}\sigma \bar{B}_{a w} \\
\mathrm{~cm}^{3} / \mathrm{mol}\end{array}$ & $\begin{array}{c}-\bar{B}_{a w}{ }^{\mathrm{a}} \\
\mathrm{cm}^{3} / \mathrm{mol}\end{array}$ & $\begin{array}{c}\sigma \bar{B}_{a w} \\
\mathrm{~cm}^{3} / \mathrm{mol}\end{array}$ & $\begin{array}{c}-B_{a w} \\
\mathrm{~cm}^{3} / \mathrm{mol}\end{array}$ & $\begin{array}{c}{ }^{\sigma} B_{a w} \\
\mathrm{~cm}^{3} / \mathrm{mol}\end{array}$ & & \\
\hline-35 & 64.91 & 7.45 & & & & & & \\
\hline-20 & 50.15 & 3.96 & & & 48.2 & 3.2 & & \\
\hline 0 & 38.01 & 1.92 & & & 42.0 & 3.0 & 50.4 & 62.0 \\
\hline 10 & & & & & 39.3 & 3.0 & 47.3 & 58.1 \\
\hline 15 & 34.91 & 3.44 & & & 37.6 & 2.9 & 45.4 & 56.1 \\
\hline 20 & & & & & 36.8 & 2.9 & 43.9 & 54.4 \\
\hline 30 & & & & & 34.5 & 2.8 & 41.0 & 51.1 \\
\hline 40 & & & & & 32.3 & 2.7 & 38.2 & 48.1 \\
\hline 50 & & & 23.16 & 0.39 & 30.4 & 2.7 & 35.8 & 45.2 \\
\hline 60 & & & & & 28.5 & 2.6 & 33.5 & 42.5 \\
\hline
\end{tabular}

a $\bar{B}_{a w}=$ mean value along an isotherm.

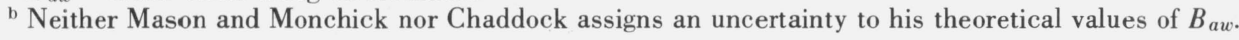


A set of $B_{a w}$ values were calculated by an empirical equation given by Goff [2], and converted to units consistent with those employed in this paper. The standard deviation ascribed to the Goff values were derived from the tolerances he assigned, which were stated to be two times the estimated probable error. The values are given in table 9 .

No attempt was made to estimate the systematic errors in the above values of $B_{a w}$. The standard deviations indicate only the precision of the measurements.

Mason and Monchick [5] and Chaddock [4] have made statistical mechanical calculations of $B_{a w}$ by assuming that the forces between air and water vapor molecules can be represented by the Lennard-Jones (12-6) potential and that the separate species potential parameters $\epsilon_{0}$ (the depth of the potential "well") and $\sigma_{0}$ (molecular "diameter") can be combined by simple combination rules. Their calculations have been extended to encompass our temperature range of interest and the values so obtained are given in table 9 . experimental data [39]. The NBS values of $\boldsymbol{B}_{a w}$ are smaller in absolute value than these other three sets of values. Although the NBS, Webster and the $50^{\circ} \mathrm{C}$ Politzer and Strebel values appear to fall on a smooth curve, this may be fortuitous. Until there is additional experimental corroboration, this apparent consistency should be viewed with reservation.

\section{Smoothing Function}

Given experimental values of $B_{a w}$ over a reasonable temperature range, it is feasible to determine the form of the interaction potential between the water vapor and air species and therefore, to derive a theoretically based expression for interpolation and extrapolation of $B_{a w}$. Unfortunately the NBS data is too limited in temperature range to warrant this approach.

A polynomial equation was fitted, therefore, to the NBS, Politzer and Strebel, and Webster data. The resultant expression is as follows:

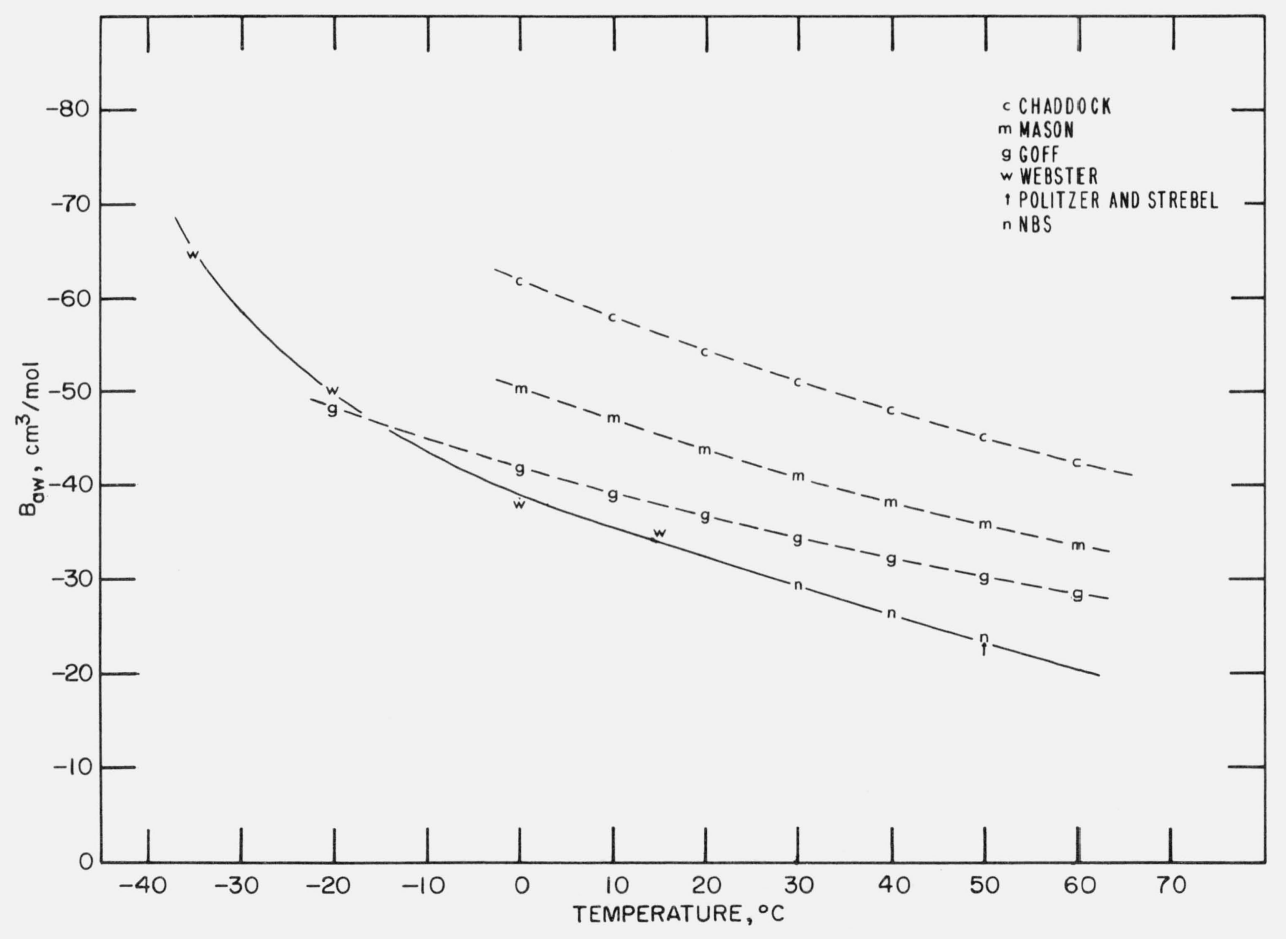

FIGURE 3. $\mathrm{B}_{\mathrm{aw}}$ versus temperature, from various investigators.

These several sets of values of $B_{a w}$ are compared graphically in figure 3 . The curves representing the Goff, Mason and Monchick, and Chaddock values are similar in shape but displaced from each other. It is not surprising that the curves are alike for they are based on similar theoretical formulations, but with somewhat different potential constants. Even Goff's empirical equation is based on values calculated from a potential function similar to the Lennard-Jones that had been adjusted to yield results consistent with his

$$
-B_{a w}=\sum_{i=0}^{4} D_{i} t^{i}
$$

where $D_{i}$ are empirical coefficients, $t$ is the temperature in $\operatorname{deg}$ Celsius and $B_{a w}$ is in units of $\mathrm{cm}^{3} / \mathrm{mol} . D_{i}$ are listed in table 10, along with the residual standard deviation of the fit. The experimental and predicted values are compared in table 11.

The differences between the experimental and predicted values are well within the standard deviation of 
the mean of the experimental values. The maximum deviation of this equation from NBS values of $B_{a w}$ is 1.1 percent.

TABLE 10. Coefficients to eq (37)

\begin{tabular}{l|l}
\hline \hline $\mathrm{D}_{0}$ & 38.9221 \\
$\mathrm{D}_{1}$ & -.384587 \\
$\mathrm{D}_{2}$ & $+.512266 \times 10^{-2}$ \\
$\mathrm{D}_{3}$ & $-.117467 \times 10^{-3}$ \\
$\mathrm{D}_{4}$ & $+.878093 \times 10^{-6}$ \\
$\sigma_{\text {res }}$ & $.842 \mathrm{~cm}^{3} / \mathrm{mol}$ \\
\hline
\end{tabular}

where $Z$ is a lattice coordination number (assuming a local crystal structure), $N_{0}$ is Avogadro's number, $\epsilon_{i j}$ are interaction energies between the designated molecular species.

Let the mole fractions $x_{i}$ in eq (38) be converted to moles $n_{i}$. Differentiating with respect to $n_{w}$ we obtain.

$$
\frac{\partial\left(\Delta G_{\mathrm{mix}}^{E}\right)}{\partial n_{w}}=W x_{a}^{2}
$$

This equation gives the excess chemical potential of the water with dissolved air over that predicted from

TABLE 11. Comparison of experimental and predicted values of $\mathrm{B}_{\mathrm{aw}}$

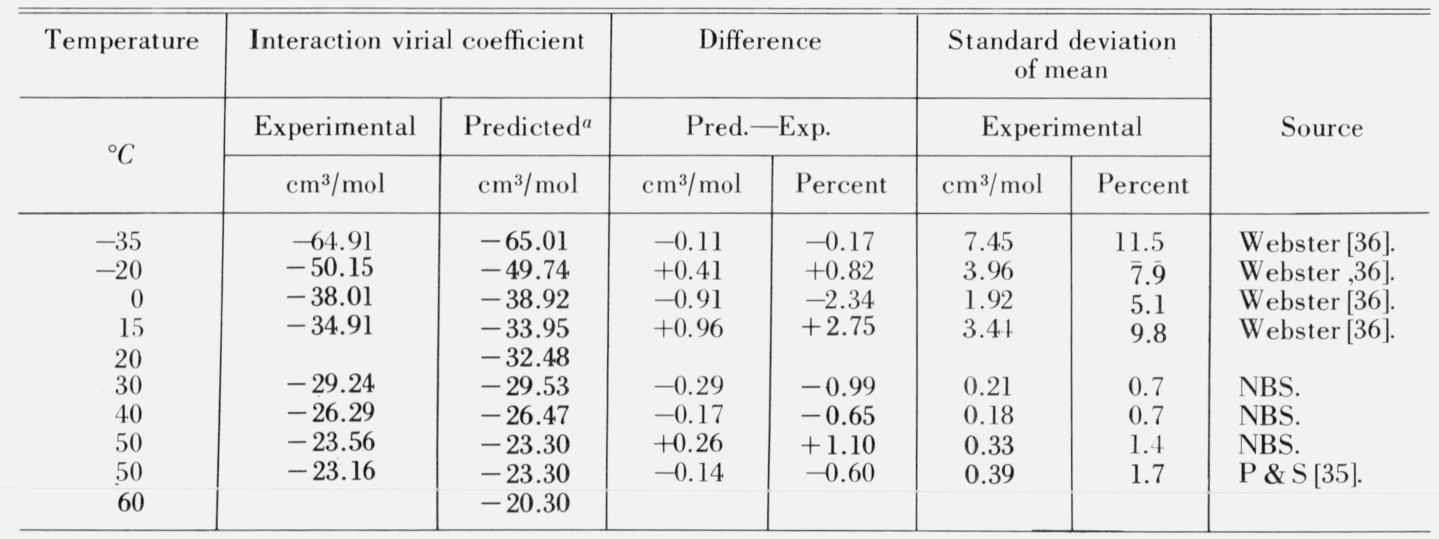

${ }^{a}$ Calculated using eq (37).

Equation (37) is offered as a suitable smoothing function for $B_{a w}$ that is valid from 30 to $50^{\circ} \mathrm{C}$, the temperature range of the NBS experiments. We feel confident in using it from 10 to $60^{\circ} \mathrm{C}$. Because it fits the Webster data well, and within the uncertainty of that data, the equation may be used to $-35^{\circ} \mathrm{C}$. However, it should be noted that the systematic uncertainty in the Webster data is unknown so that the reliability of the predicted $B_{a w}$ in the temperature range below, say, $10^{\circ} \mathrm{C}$ is unresolved.

\section{Appendix 1}

For a two component solution of equal-size molecules, such as air dissolved in water, it can be shown [7] that

$$
W\left(n_{a}+n_{w}\right) x_{a} x_{w}=\Delta G_{\text {mix }}^{E}
$$

where $\Delta G_{\text {mix }}^{E}$ is the excess Gibb's function ${ }^{7}$, that is, the departure from that predicted through Raoult's law; $n_{a}$ and $n_{w}$ are the total number of moles of air and water; and $x_{a}$ and $x_{w}$ are mole fractions of air and water. The parameter $W$ is given by [7]

$$
W=\frac{Z N_{0}}{2}\left(2 \epsilon_{a w}-\epsilon_{a a}-\epsilon_{w w}\right)
$$

${ }^{7}$ Lewis and Randall [7] call this the excess free energy of mixing and designate it by the symbol $\Delta F_{\text {mix }}^{E}$
Raoult's law and is therefore equivalent to the term $C$ in eqs (18), (19), and (22).

Mason and Monchick [5] and Chaddock [4] both give $\epsilon_{a a} / k=99.2 \mathrm{~K}$ and $\epsilon_{w w} / k=380 \mathrm{~K}$ (where $k$ is Boltzmann's constant). Mason and Monchick give values of 194 and $222 \mathrm{~K}$ for $\epsilon_{a w} / k$, as determined from second virial coefficient data and viscosity data respectively whereas Chaddock gives $220.5 \mathrm{~K}$. For the present purpose, assume $\epsilon_{a w} / k=210 \mathrm{~K}$. If a coordination number of 15 (which should lead to a conservatively large estimate of $C$ ) is assumed, then $W$ is $-3.69 \times 10^{4}$ bar $\mathrm{cm}^{3} / \mathrm{mol}$. Suppose that this is in error by a factor of 5 , then $W$ might be of the magnitude $-1.84 \times 10^{5}$ bar $\mathrm{cm}^{3} / \mathrm{mol}$.

The mole fraction of air dissolved in water $x_{a}$ may be estimated from Henry's law using the constants in table 3. The worst case (i.e., the largest value of $x_{a}$ which, in turn maximizes $C$ ) occurs at $0^{\circ} \mathrm{C}$ and 100 bars. Using this value for $x_{a}$ and $W=-1.84 \times 10^{5}$ atm $\mathrm{cm}^{3} / \mathrm{mol}$, the magnitude of $C$ is then $0.7 \mathrm{bar} \mathrm{cm}^{3} / \mathrm{mol}$.

Equation (30), with the $C$ term included, can be approximated by

$$
B_{a w} \approx[\text { Various terms }]-\frac{g(T, P)}{2 P}-\frac{C}{2 P}
$$

The lowest pressure present in the NBS enhancement data is 10 bars. The maximum contribution of $C$ to $B_{a w}$, therefore, is about $0.035 \mathrm{~cm}^{3} / \mathrm{mol}$. For $B_{a w}$ of the order 
of $26 \mathrm{~cm}^{3} / \mathrm{mol}$, the relative contribution of $C$ to $B_{a w}$ is about 1.3 parts in 1000 , which is about one order of magnitude smaller than the estimated uncertainty in $B_{a w}$.

\section{Appendix 2}

The equations for the virial coefficients for water are essentially those of Goff [2]. $B_{w w}$ is given here with opposite sign to conform to eq (8a). $C_{w w w}$ is a modification of Goff's equation to conform to eq (8a). Goff suggests the use of his equation for $C_{w w w}$ only at temperatures 60 to $100^{\circ} \mathrm{C}$ whereas we extropolate it to $-20^{\circ} \mathrm{C}$. Although this is a potentially dangerous procedure, no other alternative is available.

The equations for the virial coefficients $B_{a a}$ and $C_{a a a}$ were obtained by fitting the Sengers et al. data [16] and the Hilsenrath et al. data [14] respectively, over the temperature range 260 to $380 \mathrm{~K}$, to polynomials.

The equations for the interaction virial coefficients $C_{\text {aaw }}$ and $C_{\text {aww }}$ were similarly obtained by fitting the Mason and Monchick [5] values from -20 to $+120^{\circ} \mathrm{C}$ and the Hyland and Mason [19] values from 0 to $100{ }^{\circ} \mathrm{C}$, respectively, to polynomials.

The standard deviations of the fits for the latter four equations are given. These equations are: convenient empirical relationships and it is not intended that they be used beyond the fitted temperature ranges.

$$
\begin{aligned}
& B_{w w}=33.97-\frac{55306}{T} \times 10^{\frac{72000}{T^{2}}} \mathrm{~cm}^{3} / \mathrm{mol} \\
& C_{w w w}=2.85558 \frac{B_{w w}^{3}}{T}+B_{w w}^{2} \mathrm{~cm}^{6} / \mathrm{mol}^{2} \\
& B_{a a}=-13.521+0.24234 t-0.10022 \times 10^{-2} t^{2} \\
& +0.26880 \times 10^{-5} t^{3} \mathrm{~cm}^{3} / \mathrm{mol} ; \sigma=0.024 \\
& C_{\text {aaa }}=1314.2-0.89453 t-0.36372 \times 10^{-2} t^{2} \\
& +-.48378 \times 10^{-4} t^{3}-0.18897 \times 10^{-6} t^{4} \mathrm{~cm}^{6} / \mathrm{mol}^{2} ; \\
& \sigma=0.17 \\
& C_{\text {aaw }}=860.79-2.4203 t+0.92144 \times 10^{-2} t^{2} \\
& -0.14568 \times 10^{-4} t^{3} \mathrm{~cm}^{6} / \mathrm{mol}^{2} ; \sigma=0.32 \\
& C_{\text {aww }} \times 10^{-6}=-0.20263+0.52695 \times 10^{-2} t \text {. } \\
& -0.74761 \times 10^{-4} t^{2}+0.57576 \times 10^{-6} t^{3} \\
& -0.18065 \times 10^{-8} t^{4} \mathrm{~cm}^{6} / \mathrm{mol}^{2} ; \sigma=0.614 \times 10^{-3} \\
& T=t+273.16, t=\text { degrees Celsius. }
\end{aligned}
$$

\section{References}

[1] Keyes, F. G., and Smith, L. B., The present state of psychrometric data, Refrig. Eng. 27, 127 (1934).

[2] Goff, J. A., Standardization of thermodynamic properties of moist air, Heating, Piping, and Air Cond. 21, 118 (1949).
[3] Haar, L., and J. M. H. L. Sengers, The solubility of condensed substances in dense gases and the effect on PVT properties, J. Chem. Phys. 52, 5069 (1970).

[4] Chaddock, J. B., Moist air properties from tabulated virial coefficients, Humidity and Moisture, Vol. III, A. Wexler and W. A. Wildhack, Eds. (Reinhold Publishing Corp., New York, 1965), p. 273.

[5] Mason, E. A., and Monchick, L., Survey of the equation of state and transport properties of moist gases, Humidity and Moisture, Vol. III, A. Wexler and W. A. Wildhack, Eds. (Reinhold Publishing Corp., New York, 1965), p. 257.

[6] Hyland, R. W., and Wexler, A., The enhancement of water vapor in air, J. Res. Nat. Bur. Stand. (U.S.), 77A (Phys. and Chem.), No. 1, (Jan.:Feb. 1973).

[7] Lewis, G. N., and Randall, M., Thermodynamics, 2nd Edition, as revised by Pitzer, K. S., and Brewer, L. (McGraw-Hill Book Co., New York, 1961), Ch. 21.

[8] Hirshfelder, J. O., Curtiss, C. F. and Bird, R. B., The Molecular Theory of Gases and Liquids (John Wiley \& Sons, Inc., New York, 1954).

[9] Hanley, H. J. M., and Klein, M., On the selection of the intermolecular potential function: application of statistical mechanical theory to experiment, Nat. Bur. Stand. (U.S.), Tech. Note 360,85 pages (Nov. 1967).

[10] Harrison, L. P., Fundamental concepts and definitions, Humidity and Moisture, Vol. III, A. Wexler and W. A. Wildhack, Eds. (Reinhold Publishing Corp., New York, 1964), p. 8.

[11] Hasegawa, S., Hyland, R. W., and Rhodes, S. W., A comparison between the National Bureau of Standards two-pressure humidity generator and the National Bureau of Standards standard hygrometer, Humidity and Moisture, Vol. III, A. Wexler and W. A. Wildhack, Eds. (Reinhold Publishing Corp., New York, 1964), p. 455.

[12] Kell, G. S., and Whalley, E., The PVT properties of water I. Liquid water in the temperature range 0 to $150{ }^{\circ} \mathrm{C}$ and at pressures up to $1 \mathrm{~kb}$, Phil. Trans. Roy. Soc. London, Series A, 258, 565 (1965).

[13] Kell, G. S., Precise representation of volume properties of water at one atmosphere, J. Chem. Eng. Data 12, 66 (1967).

[14] Hilsenrath, J., et al., Tables of Thermal Properties of Gases, Nat. Bur. Stand. (U.S.), Circ. 564 (1955).

[15] Hall, N. A., and Ibele, W. E., The tabulation of imperfect gas properties for air, nitrogen, and oxygen, Trans. ASME 76, 1039 (1957).

[16] Sengers, J. M. H. L., Klein, M., and Gallagher, J. S., Pressurevolume-temperature relationships of gases: Virial coefficients, Report No. AEDC TR-71-39, Arnold Engineering Development Center, AFSC, Arnold Air Force Station Tennessee (1971).

[17] Wexler, A., and Greenspan, L., Vapor pressure equation for water in the range 0 to $100^{\circ} \mathrm{C}$, J. Res. Nat. Bur. Stand. (U.S.), 75A (Phys. and Chem.), No. 3, 213-230 (May-June 1971).

[18] Keyes, F. G., The thermodynamic properties of water substance $0^{\circ}$ to $150^{\circ} \mathrm{C}$, J. Chem. Phys. 15, 602 (1947).

[19] Hyland, R. W., and Mason, E. A., Third virial coefficient for air-water vapor mixtures, J. Res. Nat. Bur. Stand. (U.S.) 71A (Phys. and Chem.), No. 3.219-224 (May-June 1967).

[20] Stimson, H. F., International temperature scale of 1948, J. Res. Nat. Bur. Stand. (U.S.), 42, 209 (1949) RP1962.

[21] Stimson, H. F., International temperature scale of 1948. Text revision of 1960, J. Res. Nat. Bur. Stand. (U.S.) 65 A, (Phys. and Chem.), No. 3, 139-145 (May-June 1961).

[22] Winkler, L. W., Die Loslichkeit der Gase in Wasser, Ber. deuts. chem. Ges. 34, 1408 (1901).

[23] Winkler, L. W., Chem.-Techn. Untersuchungsmethoden, by Lunge, G., 5 ed., 1, 768 (1904). Also 1,573 (1921 ed.).

[24] Dorsey, N. E., Properties of Ordinary Water Substance (Rheinhold Publishing Corp., New York, N.Y., 1940).

[25] Loomis, A. G., Solubilities of gases in water, International Critical Tables, Vol. 3, E. W. Washburn, Ed. (McGraw-Hill Book Co., New York, 1928), p. 255.

[26] Jones, H. B., Solubilities of various gases in water, Handbook of Chemistry and Physics, 33rd. edition, C. D. Hodgman, Ed. (Chemical Rubber Publishing Co., Cleveland, Ohio, 1951), p. 1482.

[27] Coste, J. H., Review of Nitrogen Solubilities, J. Phys. Chem. 31 , 81 (1927). 
[28] Van Slyke, D. D., Dillion, R. T., and Margaria, R., Studies of gas and electrolyte equilibria in blood XVIII, Solubility and physical state of atmospheric nitrogen in blood cells and plasma, J. Biol. Chem. 105, 571 (1934).

[29] Wiebe, R., Gaddy, V. L., and Heins, C., Jr., The solubility of nitrogen in water at 50,75 , and $100^{\circ} \mathrm{C}$ from 25 to 1000 atmospheres, J. Am. Chem. Soc. 55, 947 (1933).

[30] Saddington, A. W., and Krase, N. W., Vapor-liquid equilibria in the system nitrogen-water, J. A., Chem. Soc. 56, 353 (1934).

[31] Krichevsky, I. R., and Kasarnovsky, J. S., Thermodynamical calculations of solubilities of nitrogen and hydrogen in water at high pressures, J. Am. Chem. Soc. 57, 2168 (1935).

[32] Deming, W., and Shupe, L. E., Some physical properties of compressed gases I. Nitrogen, Phys. Rev. 37, 638 (1931).

[33] Division of Inorganic Chemistry, Commission on Atomic Weights, Atomic weight of the elements, Pure and Applied Chem. 21, 93 (1970).

[34] General Physical Constants, Nat. Bur. Stand. (U.S.), Spec. Publ. 344 (1971).
[35] Pollitzer, F., and Strebel, E., Über der Einfluss indifferenter Gase auf die Sättigungsdampfkonzentration von Flussigkeiten, Zeit. fur phys. Chemie 110,768 (1924).

[36] Webster, T. J., The effect on water vapor pressure of superimposed air pressure, J. S. C. I. 69, 343 (1950).

[37] Goff, J. A., and Bates, A. C., The interaction constant for moist air, Trans. ASHVE 47,373 (1941).

[38] Goff, J. A., Anderson, J. R., and Gratch, S., Final values of the interaction constant of moist air, Trans. ASHVE 49, 269 (1943).

[39] Goff, J. A., and Gratch, S., Thermodynamic properties of moist air, Heating, Piping, and Air Cond. (ASHVE Journal Sect.) 17,334 (1945).

[40] Goff, J. A., Saturation pressure of water on the new Kelvin scale, Humidity and Moisture, Vol. III, A. Wexler and W. A. Wildhack, Eds. (Reinhold Publishing Corp., New York, 1965), p. 289.

(Paper 77A1-758) 